\title{
Safety and efficacy of recombinant $\gamma$ interferon in the treatment of systemic sclerosis
}

Medical School, National University of Athens, Athens, Greece:

Department of Pathophysiology P G Vlachoyiannopoulos I Dimitriou

H M Moutsopoulos

Medical School University of Ioannina, Ioannina, Greece: Department of Internal Medicine N Tsifetaki S A Papiris

Department of Biochemistry

D Galaris

Correspondence to: H M Moutsopoulos MD, FACP, FRCP (Edin), Department of Pathophysiology Medical School, National University of Athens, $75 \mathrm{M}$ Asias Street, 11527 Athens, Greece.

Accepted for publication 21 June 1996

Panayiotis G Vlachoyiannopoulos, Niki Tsifetaki, Ioannis Dimitriou, Dimitrios Galaris, Spyros A Papiris, Haralampos M Moutsopoulos

\begin{abstract}
Objective-To evaluate the safety and efficacy of recombinant $\gamma$ interferon (rIFN $\gamma$ ) in the treatment of patients with systemic sclerosis.

Methods-Sixteen patients with systemic sclerosis were treated with r-IFN $\gamma, 60 \mu \mathrm{g}$ $\mathrm{m}^{-2}$ (low dose, $\mathrm{n}=10$ ) and $150 \mu \mathrm{g} \mathrm{m}^{-2}$ (high dose, $n=6$ ), three times weekly in an open phase I/I trial of eight months duration. The patients were stratified in low and high dose according to the severity and the extent of scleroderma; the two groups were comparable.

Results-The treatment was well tolerated. The most common side effects, almost certainly related to $\mathbf{r}-\mathrm{IFN} \gamma$, were fever, chills, dizziness, headache, and severe flu-like syndrome with decreasing intensity with the time of treatment. Severe aphthous stomatitis $(n=1)$, ventricular tachycardia $(n=1)$, severe oesophageal ulcers due to gastrooesophageal reflux $(n=1)$, disease exacerbation alone with frank arthritis and slight pericardial effusion $(n=1)$, and inability to conform to the requirements of the study $(n=1)$ were the reasons for discontinuing treatment. Side effects and degree of response were evident during the first five months of treatment. A significant decrease in mean skin thickness score was observed and was higher in the high dose group. Reactive oxygen species of peripheral neutrophils and soluble interleukin-2 receptor serum concentrations were higher than those of normal individuals at study entry and decreased in parallel with clinical improvement.

Conclusions-Treatment of systemic sclerosis patients with $\mathbf{r}-\mathbf{I F N} \gamma$ was relatively safe and well tolerated for doses as high as $150 \mu \mathrm{g} \mathrm{m}^{-2}$ three times weekly. Side effects and the degree of response can be seen during the first months of therapy and can be used as predictors of ultimate toxicity or response. The drug seems to be effective in treating cutaneous scleroderma.
\end{abstract}

\section{(Ann Rheum Dis 1996;55:761-768)}

Systemic sclerosis is a multisystem disorder of unknown aetiology, characterised by deposition of excessive amounts of collagen in the skin and internal organs. ${ }^{1}$ Activation of $\mathrm{T}$ lymphocyte subpopulations and fibroblasts plays a key role in the development of the disease, ${ }^{2}{ }^{3}$ and is probably linked to the hyper-reactivity of the immune system, ${ }^{4-7}$ and to the vascular damage observed in the early disease stages. ${ }^{8-11}$ An increased in soluble interleukin-2 receptors (SIL-2R) has been observed in the sera of systemic sclerosis patients and reflect the activation of T lymphocytes. ${ }^{72}$ Peripheral neutrophils, also activated in systemic sclerosis patients, produce high levels of reactive oxygen species (ROS) which have been associated with the severity and the extent of skin involvement. ${ }^{13} \gamma$ Interferon (IFN $\gamma$ ) has been shown to inhibit collagen synthesis by normal dermal fibroblasts and by systemic sclerosis fibroblasts in vitro. ${ }^{15-17}$ Encouraging results regarding safety and efficacy of recombinant IFN $\gamma(\mathrm{r}-\mathrm{IFN} \gamma)$ in treating systemic sclerosis in previous studies, ${ }^{18-20}$ stimulated us to undertake a pilot phase I/II open clinical trial for systemic sclerosis patients in order to further test the safety and clinical and biological effectiveness of r-IFN $\gamma$. Although definite answers about efficacy can be obtained only by placebo controlled trials, ${ }^{12}$ phase I/II trials are nevertheless important to establish a substantial safety database and to answer questions relating toxicity to the extent and duration of biological effects induced by the drug.

\section{Methods}

Sixteen patients (15 female, one male) were enrolled in a phase I/II clinical study, (table 1). The patients had clinical evidence of sclerodermatous skin involvement (oedematous or hidebound) proximal to wrist, ankle, and face. Patients $6,13,14$, and 15 had skin thickening restricted to sites distal to the elbow and knee, but also involving the face and neck, and these patients were considered to have limited cutaneous systemic sclerosis (ISSc) ${ }^{21}$ The remaining patients had skin thickening centrally to the elbows and knees and nine of them (Nos 1, 2, 5, 7, 8, 9, 10, 12, and 16) had also trunk involvement; these patients were considered to have diffuse cutaneous systemic sclerosis (dSSc), ${ }^{21}$ as shown in table 1 . The sclerodermatous changes occurred during a period of 1 to 46 months before treatment. The patients were able and willing to conform to the requirements of the study and gave a written consent. Thirteen patients were followed up in the rheumatology outpatient clinic, Department of Internal Medicine, University of Ioannina, and three patients at the rheumatology outpatient clinic, Department of Pathophysiology, Laikon Hospital, National University of Athens. The following exclusion criteria were used for the selection of the patients: 
(1) Scleroderma secondary to exposure to L-tryptophan, vinyl chloride, or bleomycin,

(2) Significant internal organ damage according to the following criteria: (a) significant renal disease defined by serum creatinine $>265 \mu \mathrm{mol} \mathrm{l}^{-1}$, or renal crisis defined by a rise in diastolic blood pressure above 110 $\mathrm{mm} \mathrm{Hg}$ during the final week of observation, associated with haematuria or proteinuria; microangiopathic haemolytic anaemia, retinal haemorrhages, papilloedema, or an increase in creatinine levels over $70 \%$ of baseline; (b) significant lung involvement defined by forced vital capacity $(\mathrm{FCV})<50 \%$ and/or diffusion capacity of carbon dioxide (DLCO) $<40 \%$ of predicted; (C) significant heart involvement defined by left ventricular ejection fraction (LVEF) $<40 \%$ of predicted, or by arrhythmias requiring medical treatment; (d) significant gut involvement defined by oesophageal ulcers, diarrhoea severe enough to require antibiotic treatment, or abdominal pain with air fluid levels on abdominal upright radiogram in the absence of identifiable causes other than systemic sclerosis.

(3) Drug treatment that might independently influence outcome of the trial, such as: prednisolone $>10 \mathrm{mg}$ per day, angiotensin converting enzyme inhibitors, prostaglandin analogues, or therapy with D-penicillamine $\geq 500 \mathrm{mg}$ per day, methotrexate, or cyclosporin within the preceding three months.

End points suggesting discontinuation of the treatment were: doubling of serum creatinine, renal crisis, newly developed hypertension requiring angiotensin converting enzyme inhibitor therapy, FVC $<50 \%$ of predicted, DLCO to alveolar volume ratio (DLCO/VA) < $40 \%$ of predicted, LVEF $<40 \%$ of predicted, arrhythmias requiring medical treatment, multiple air fluid levels in the upright abdominal radiogram in the absence of other causes, oesophageal ulcers due to gastro-oesophageal reflux, and diarrhoea severe enough to require antibiotic treatment. Finally, doubling of skin thickness score for more than three months indicated serious disease exacerbation constituting an end point for skin involvement and suggested discontinuation of the treatment.

DOSE AND ADMINISTRATION

All patients received three weekly intramuscular injections of r-IFN $\gamma$ (specific activity $3 \times 10^{7}$ units $\mathrm{mg}^{-1}$, supplied by Boehringer-IngelheimHellas SA). The r-IFN $\gamma$ preparations were supplied, ready for use, in bottles each containing $100 \mu \mathrm{g}$ of $\mathrm{r}$-IFN $\gamma$. The $\mathrm{r}$-IFN $\gamma$ injections were given in a medical outpatient facility. Ten patients received $60 \mu \mathrm{g} \mathrm{m}^{-2}$ of r-IFN $\gamma$ per injection (low dose) and six patients received $150 \mu \mathrm{g}$ $\mathrm{m}^{-2}$ of $\mathrm{rIFN} \gamma$ (high dose) per injection.

PATIENT STRATIFICATION

The low dose group was comparable with the high dose group in terms of initial mean skin thickness score [15.3 (SD 9.4) $v 18.7$ (9.3), P
Table 1 Demographic data, disease duration, pattern of sclerodermatous skin involvement, and baseline skin thickness score in 16 patients treated with IFN (low and high dose)

\begin{tabular}{llll}
\hline \multirow{2}{*}{$\begin{array}{l}\text { Patient } \\
\text { No/sex/age } \\
\text { (years) }\end{array}$} & \multirow{2}{*}{$\begin{array}{l}\text { Pattern of } \\
\text { sclerodermatous } \\
\text { skin }\end{array}$} & \multicolumn{2}{l}{ Skin thickness score } \\
\cline { 3 - 4 } & involvement & Baseline & 8 months \\
\hline Low dose & & & \\
$1 / F / 18$ & dSSc & 19 & 6 \\
$3 / F / 50$ & dSSc & 13 & 9 \\
$4 / F / 67$ & dSSc & 14 & 17 \\
$6 / F / 52$ & ISSc & 7 & 0 \\
$9 / F / 27$ & dSSc & 30 & 17 \\
$13 / F / 59$ & ISSc & 8 & 0 \\
$15 / F / 41$ & ISSc & 8 & 4 \\
$2 / F / 45$ & dSSc & 18 & Discontinued \\
$5 / F / 61$ & dSSc & 17 & Discontinued \\
$16 / F / 34$ & dSSc & 18 & Discontinued \\
High dose & & & \\
$8 / F / 23$ & dSSc & 34 & 8 \\
$10 / F / 46$ & dSSc & 26 & 10 \\
$11 / F / 40$ & dSSc & 16 & 6 \\
$14 / F / 58$ & lSSc & 13 & 0 \\
$7 / F / 56$ & dSSc & 19 & Discontinued \\
$12 / M / 19$ & dSSc & 16 & Discontinued \\
\hline
\end{tabular}

dSSc, diffuse cutaneous systemic sclerosis; $1 \mathrm{SSc}$, limited cutaneous systemic sclerosis; $M$, male; $F$, female.

$=0.37]$, age $[45.4(15.6) v 40.3$ (16.4) years, $\mathrm{P}$ $=0.55]$, disease duration [15.5 (12.7) $v 22.3$ (16.5) months, $\mathrm{P}=0.66]$, DLCO [73 (21) $v 67$ (24) $\%$ predicted, $\mathrm{P}=0.87$ ], LVEF [70 (10) $v$ 70 (9) \% predicted, $\mathrm{P}=0.87], \mathrm{Po}_{2}[11.3(0.73)$ $v 12.2(1.06) \mathrm{kPa}, \mathrm{P}=0.12]$, and presence of gastro-oesophageal reflux $(6 / 10 v 3 / 6$ patients positive). Treatment with r-IFN $\gamma$ was scheduled for eight months.

PREVIOUS AND CONCOMITANT TREATMENT

Patients $1,2,9,12$, and 16 had received a previous drug treatment: $\mathrm{D}$-penicillamine (patients 1 and 12) or methotrexate. Treatment was discontinued because of side effects (patient 2) or no response (the remaining patients). Five patients from the low dose group and two patients from high dose group were taking $20 \mathrm{mg}$ omeprazole daily for gastrooesophageal reflux. Two additional patients, one from each group, received omeprazole during the study after institution of $\mathrm{r}$-IFN $\gamma$ treatment because of gastro-oesophageal reflux. Three patients from the low dose group and two patients from the high dose group were receiving $7.5-10 \mathrm{mg}$ prednisolone at study entry, and one patient (patient 12) also received prednisolone $10 \mathrm{mg}$ daily after institution of rIFN $\gamma$ treatment. Two patients from the low dose group and two from the high dose group were taking acetylsalicylic acid $100 \mathrm{mg}$ per day.

STUDY EVALUATION

A history was taken and physical examination performed at study entry, at two week intervals for the first two months, and each month thereafter. One physician was responsible for selecting patients, keeping their records, and managing the patients' problems related either to their disease or to their treatment. Three other doctors, unaware of the treatment, participated in the study as follows. A cardiologist evaluated the heart by echocardiogram for cardiac effusion, valve abnormalities, and measurement of left ventricular ejection 
fraction at baseline, and after four, six, and eight months of treatment. A pulmonary physician evaluated lung function by clinical examination. This involved assessing and grading dyspnoea using a well accepted dyspnoea scoring system ${ }^{22}$ at each patient visit; spirometric evaluation at baseline and at four and eight months of treatment; and measuring arterial oxygen pressure with the patient at rest, at baseline and at four and eight months of treatment. A chest $x$ ray was taken at baseline and at the end of the study, and interstitial lung disease was assessed as previously described. ${ }^{22}$ One physician evaluated kidney function and the skin thickness score at each patient visit. Skin involvement was assessed at each patient visit by measuring a skin thickness score, according to a modification of the system described by Kahaleh et $a l^{23}$ as follows: the body was divided into 15 zones-head and neck, anterior chest, anterior abdomen, posterior chest, buttocks, and five bilateral sites: upper arm, forearm and dorsum of hands, thigh, lower leg, and dorsum of the feet. Patients with scleroderma limited to the fingers and face were not included in the study; therefore measurement of sclerodactyly in the fingers was not included in the evaluation of the total skin score. The gradings were: 0 , normal skin; 1, thickened skin; 2, thickened and unable to pinch; 3 , thickened and unable to move. Individual zone scores were summed to obtain a total score. Therefore the range of possible skin thickness scores was from 2 (patient with mild skin involvement above the wrists) to 45 (patient with trunk involvement). In addition, at each patient visit, the oral aperture was measured as the distance from the upper to the lower denture borders on full, active mouth opening. All the patients enrolled in the study were followed up on the same day as other patients with systemic sclerosis who did not participate in the study. Complete blood cell count, platelets, erythrocyte sedimentation rate, prothrombin time, serum electrolytes, serum glutamic oxaloacetic transaminase (SGOT), serum glutamic pyruvic transaminase (SGPT), alkaline phosphatases; lactic dehydrogenase, albumin, serum creatinine, cholesterol, triglycerides, and urinalysis were performed at each visit.

\section{AUTOANTIBODIES IN THE SERA OF PATIENTS \\ UNDER STUDY}

Antinuclear antibodies (ANA) were detected by indirect immunofluorescence using Hep-2 cells as substrate. In addition, antibodies to extractable cellular antigens were evaluated in all the patients using both counterimmunoelectrophoresis and western blotting. ${ }^{24}$ The sera of all the patients were positive for ANA in a titre ranging from $1 / 320$ to $1 / 1280$ with a fine speckled pattern, with the exception of the sera from patients 15 and 16 which gave a pattern compatible with the presence of anticentromere antibodies (ACA). Counterimmunoelectrophoresis revealed that the sera of patients $1,4,5,9$, and 12 were positive for anti-topoisomerase-I antibodies (anti-topoI). The presence of anti-topo-I and ACA was reconfirmed with western blotting. Antibodies to U1RNP, SmRo/SSA, and La/SSB were not detected in the sera under study.

MEASUREMENTS OF REACTIVE OXYGEN SPECIES OF PERIPHERAL NEUTROPHILS

At baseline and after three months of treatment with r-IFN $\gamma$, peripheral neutrophils of the patients were isolated from $25 \mathrm{ml}$ of blood by ficoll-hypaque density gradient centrifugation as previously described ${ }^{25}$ and $1.5 \times 10^{6}$ cells in $1 \mathrm{ml}$ of Roswell Park Memorial Institute (RPMI 1640) medium were activated by $200 \mu \mathrm{g} \mathrm{ml}^{-1}$ phorbol myristate acetate (PMA) in the presence of $80 \mu \mathrm{M}$ cytochrome $C$; the reduction of cytochrome $C$ was measured by a Shimatzu spectrophotometer as previously described. ${ }^{25}$ Reduction of cytochrome $C$ was used as a measure of the production of reactive oxygen species (ROS) by the neutrophils as previously described. ${ }^{25}$ The patients were free of r-IFN $\gamma$ on the day of blood sampling as well as on the previous day, and in each experiment one or two patient samples were tested along with two samples of age and sex matched normal individuals.

SOLUBLE INTERLEUKIN-2 RECEPTOR IN THE SERA OF PATIENTS

The soluble interleukin-2 receptor (SIL-2R) was determined by the CELLFREE interleukin-2 receptor test kit ( $T$ Cell Diagnostics) according to the manufacturers' instructions: $50 \mu$ l of standard kit controls and sera tested in duplicates from patients and from 50 normal individuals were pipetted into a microtitre plate and precoated with murine monoclonal antibody to human IL-2R along with $50 \mu$ lof a second murine monoclonal antibody to human IL-2R conjugated with horseradish peroxidase. The plate was incubated for $3 \mathrm{~h}$ on a rotator at room temperature, washed thoroughly, and $100 \mu \mathrm{l}$ of a chromogen solution were pipetted into the wells. After $30 \mathrm{~min}$ incubation at room temperature the reaction was stopped and the absorbance was read at $490 \mathrm{~nm}$. The samples values were determined from a standard curve.

\section{STATISTICAL ANALYSIS}

A paired difference $t$ test on each patient's skin score, oral aperture, LVEF \% predicted, DLCO \% predicted, $\mathrm{PO}_{2}$ at baseline versus four, six, and eight months of treatment was performed to evaluate the effects of treatment on skin, heart and lung involvement. One way analysis of variance (ANOVA) was performed in order: (a) to evaluate the effects of the treatment on the ability of the patients' peripheral neutrophils to produce reactive oxygen species in response to PMA, at baseline versus three months of therapy, and compare this with the ability of peripheral neutrophils from age and sex matched normal individuals to produce reactive oxygen species; and (b) to compare the SIL-2R sera levels before and after r-IFN $\gamma$ treatment with the SIL2R sera levels of normal individuals. Regression analysis was performed as a tool: (a) to identify a relation between oral aperture and skin thickness score, and (b) to identify a relation 
between skin thickness score, oral aperture, LVEF \% predicted, and DLCO \% predicted with the duration of treatment. A MannWhitney $U$ test was performed to compare the low with the high dose group in terms of age, disease duration, DLCO \% predicted, $\mathrm{PO}_{2}$ $(\mathrm{kPa}), \mathrm{LVEF} \%$ predicted, and skin thickness score. The Spearman rank correlation coefficient was used to test the hypothesis that there is a trend in pulmonary and heart function as the skin score and/or oral aperture change.

\section{Results}

SKIN THICKNESS SCORE

As shown in table 1, the patients were subdivided into those receiving low dose of IFN $\gamma\left(60 \mu \mathrm{g} \mathrm{m}^{-2}\right)$ and those receiving high dose $\left(150 \mu \mathrm{g} \mathrm{m}^{-2}\right)$. Four patients (patients 2, 5, 7, and 12) withdrew from the study after treatment for $18,17,19$, and 16 weeks respectively because of severe oesophageal ulcers, exacerbation of the skin involvement, personal reasons (one patient moved to another country), and severe aphthous stomatitis respectively. One additional patient (No 16) discontinued treatment after the third injection of r-IFN $\gamma$ because of ventricular tachycardia.

Individual skin thickness scores at study entry and after eight months of treatment are shown in table 1. The mean skin thickness score decreased from an average of 17 at study entry to 7 at the end of treatment in the 11 patients who completed the study, with a mean percentage change in skin thickness score of $-60.5 \%$. The mean skin thickness score also decreased in the patients who discontinued treatment, from 15.5 at baseline to 14.8 , with a mean percentage change in skin thickness score of $-23.5 \%$. Statistical analysis using a paired difference $t$ test on each patient's skin score at baseline versus four months of treatment indicated a statistically significant decrease in the mean skin thickness score for 15 patients who completed four months of treatment $(P<0.001)$. In addition, for the 11 patients who completed the study the mean skin thickness score also decreased significantly at baseline versus eight months of treatment $(P<0.009)$. However, the decrease of mean skin thickness score from the fourth to the eighth month of treatment was not significant $(P=0.6)$.

In general the mean skin thickness score was inversely related to the duration of treatment as shown by regression analysis $(r=0.95, \mathrm{P}=$ 0.00052 , fig 1) The distance from the upper to the lower denture borders on full active oral aperture was measured at each visit and increased by the duration of treatment $(r=$ $0.95, \mathrm{P}<0.0005$, fig 2). Furthermore, there was a significant inverse correlation between the skin thickness score and the oral aperture $(r$ $=0.92, \mathrm{P} .<0.00052)$. An effort was undertaken to compare the effects of therapy in patients receiving high dose $\left(150 \mu \mathrm{g} \mathrm{m}^{-2} ; \mathrm{n}=6\right)$ and low dose $\left(60 \mu \mathrm{g} \mathrm{m}^{-2} ; \mathrm{n}=9\right)$ r-IFN $\gamma$. Patients receiving high dose rIFN $\gamma$ experienced a greater reduction of skin thickness score than patients receiving low dose r-IFN $\gamma$ : the mean skin thickness score decreased from an average of 18.7 to $5.3(\mathrm{P}<0.001)$ in the high dose group, while it decreased from an average of 15.3 to $10.8(P=0.089)$ in the low dose group. At the end of the study the mean skin thickness score was significantly lower in the high dose group $(P=0.039)$. In general a decrease in skin thickness was more evident in the trunk, face, and upper arms, while the skin thickness was more resistant to the treatment in forearms, dorsum of hands, and fingers.

\section{PULMONARY FUNCTION BEFORE AND AFTER} r-IFN $\gamma$ TREATMENT

Patients 3 and 9 had grade 4 dyspnoea score at study entry, which remained unchanged throughout the study. The remaining patients had a grade 0 dyspnoea score at study entry and of these, patient No 4 developed grade 4 dyspnoea score and patient No 13 grade 1 dyspnoea score at the end of the study. Patients 4 , 9,13 , and 15 had a grade 1 interstitial pattern on chest $x$ ray at study entry, which remained unchanged at the end of the study, while patients 3 and 14 had a grade 2 interstitial pattern which remained also unchanged. Patient No 7 had a grade 4 interstitial pattern at study entry and a grade 2 interstitial pattern at the end of the study. The $\mathrm{PO}_{2}$ values were correlated with the LVEF \% predicted values measured by echocardiography $(P=0.028)$. Statistical analysis using a paired difference $t$ test on each patient's forced expiratory volume in one second $\left(\mathrm{FEV}_{1}\right)$, forced vital capacity (FVC), and DLCO values at baseline versus four, six, and eight months of treatment showed that the changes in these indices over the course of the treatment period were not significant compared to the baseline values. Differences related to dose of r-IFN $\gamma$ were not observed.

CARDIOLOGICAL EVALUATION BEFORE AND AFTER r-IFN $\gamma$ TREATMENT

One patient had ventricular premature beats that did not require therapeutic intervention before the institution of r-IFN $\gamma$ treatment. The first injections of r-IFN $\gamma$ were therefore given in an inpatient setting with close monitoring by $24 \mathrm{~h}$ Holter; this showed ventricular tachycardia after the third injection of r-IFN $\gamma$.

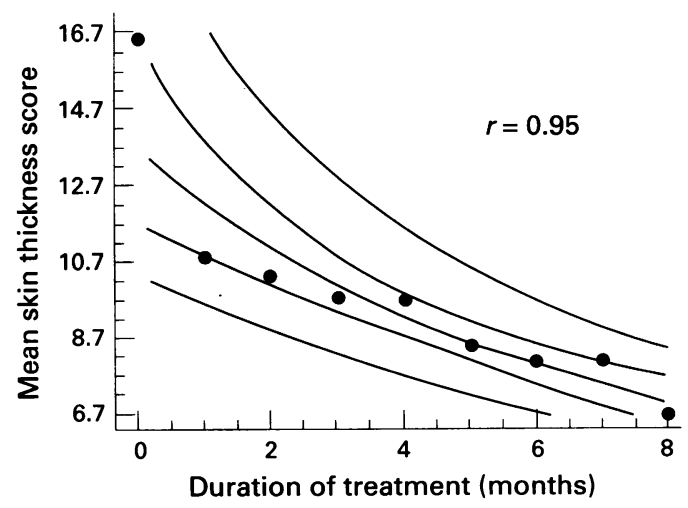

Figure 1 Correlation of the mean skin thickness score with the duration of treatment. 


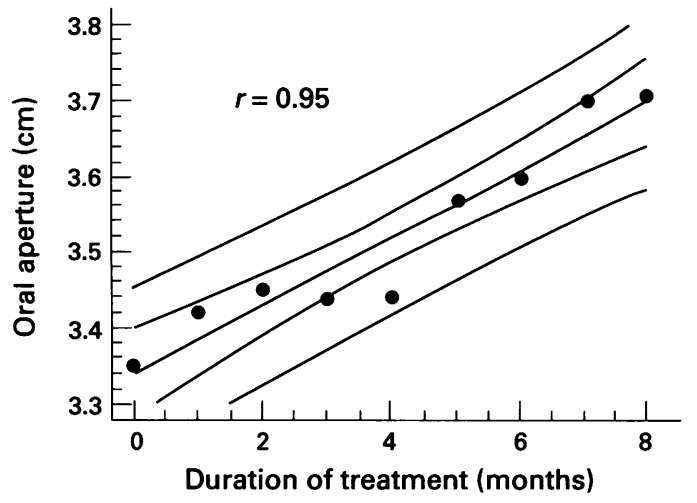

Figure 2 Correlation of the oral aperture with the duration of treatment. The inverse correlation indicates that an increase of the oral aperture was observed during treatment. This is compatible with improvement of systemic sclerosis with rIFNy.

The treatment was therefore discontinued and the electrocardiographic findings reverted to normal.

Ultrasonographic examination of the heart revealed a slight pericardial effusion in patient No 11 at study entry. Follow up ultrasound revealed no change in the effusion at the end of the study.

Patient No 5, who discontinued treatment after 17 weeks, presented with a slight pericardial effusion one month earlier, together with the exacerbation of skin thickness. The pericardial effusion in patient No 5 was asymptomatic; the treatment was discontinued because of exacerbation of skin involvement and arthritis. The fluctuations of mean LVEF $\%$ predicted values during the study did not reach statistical significance compared to the baseline levels. Differences related to dose of $r-$ IFN $\gamma$ were not observed.

GASTROINTESTINAL INVOLVEMENT IN RESPONSE TO r-IFN $\gamma$ TREATMENT

Nine out of the 15 patients (Nos $2,3,4,9,10$ $11,12,14$, and 15) experienced severe oesophageal burning due to gastrooesophageal reflux at study entry and seven of these (Nos 2, 3, 4, 9, 10,14, and 15) were taking $20 \mathrm{mg}$ of omeprazole daily (alone or with cisapride). Although patients 1 and 8 had a considerable skin involvement response to r-IFN $\gamma$, they experienced oesophageal burning due to gastro-oesophageal reflux after starting r-IFN $\gamma$ treatment. In addition, patient No 2 developed severe oesophageal ulcers which led to the discontinuation of $\mathrm{r}-\mathrm{IFN} \gamma$ treatment.

\section{SIDE EFFECTS}

Many patients had difficulty tolerating r-IFN $\gamma$. Fever was the most common side effect (this occurred in 14 patients-87.5\%). It was well tolerated by most patients and was minimised by taking $500 \mathrm{mg}$ paracetamol $2 \mathrm{~h}$ after the $\mathrm{r}$-IFN $\gamma$ injection. In four of the 14 patients who experienced fever, the symptom resolved two to four months after study entry. In the remaining patients, fever persisted as a side effect, occurring after every r-IFN $\gamma$ injection until the end of the study, but to a lesser degree after two to four months of treatment.
In 10 of the 14 patients who experienced fever, chills also occurred, accompanied by myalgia and fatigue. A severe flu-like syndrome, however, characterised by fever, myalgia, fatigue, chills, and nasal obstruction, occurred in two patients. The intensity of this reaction diminished as treatment progressed and was further reduced by paracetamol.

One male patient experienced severe aphthous stomatitis accompanied by a rise in ANA titre from $1 / 320$ to $1 / 1280$ with a fine speckled pattern, but no rise anti-dsDNA antibodies. The treatment was discontinued. Prednisolone $10 \mathrm{mg}$ daily was prescribed, together with nystatin by mouth, and the symptom resolved. After one month, injections of r-IFN $\gamma$ were repeated and the same symptom occurred again after the third injection. The patient did not experience arthritis, rash, or renal involvement while his scleroderma was in remission. Thus the severe aphthous stomatitis in this patient should be considered an adverse reaction almost certainly related to r-IFN $\gamma$.

One female patient (No 16, table 2) with premature ventricular beats before the institution of $\mathrm{r}-\mathrm{IFN} \gamma$ treatment experienced ventricular tachycardia detected by $24 \mathrm{~h}$ Holter monitoring after the injection of r-IFN $\gamma$ and the drug was discontinued.

One patient (No 3) with advanced pulmonary disease at study entry experienced arthralgia after the first injection of r-IFN $\gamma$. Despite some improvement in skin thickness, her pulmonary function did not improve. Although arthralgia could be considered to be a symptom related to exacerbation of systemic sclerosis, the improvement of skin involvement in this patient indicates that arthralgia occurring shortly after r-IFN $\gamma$ injection was probably an adverse reaction to r-IFN $\gamma$.

One patient (No 5) developed frank arthritis in wrists, metacarpal and proximal interphalangeal joints, knees, and ankles, as well as doubling of skin thickness score which persisted for more than three months. The same patient developed blurred vision transiently and a non-symptomatic pericardial effusion. Her ANA titre rose from 1/320-fine speckled pattern to $1 / 1280$ with the same pattern, while anti-dsDNA antibodies were not found and the complement levels remained within normal limits.

One patient developed pruritus, hypertrichosis in the shoulders, upper arms and face, and hoarseness. Ultrasonographic examination of the ovaries did not reveal a tumour and computerised tomography of the abdomen did not reveal an adrenal tumour. Plasma testosterone and 17-hydroxyprogesterone levels were within normal limits.

Another patient also developed hoarseness.

REACTIVE OXYGEN SPECIES PRODUCTION FROM PERIPHERAL NEUTROPHILS BEFORE AND AFTER r-IFN $\gamma$ TREATMENT

Neutrophils were isolated from peripheral blood of patients and incubated for $30 \mathrm{~min}$ with PMA in the presence of cytochrome $C$ as described in Methods. The production of reactive oxygen species was assessed by measuring 
Table 2 Adverse reactions during eight months of treatment with recombinant interferon- $\gamma$

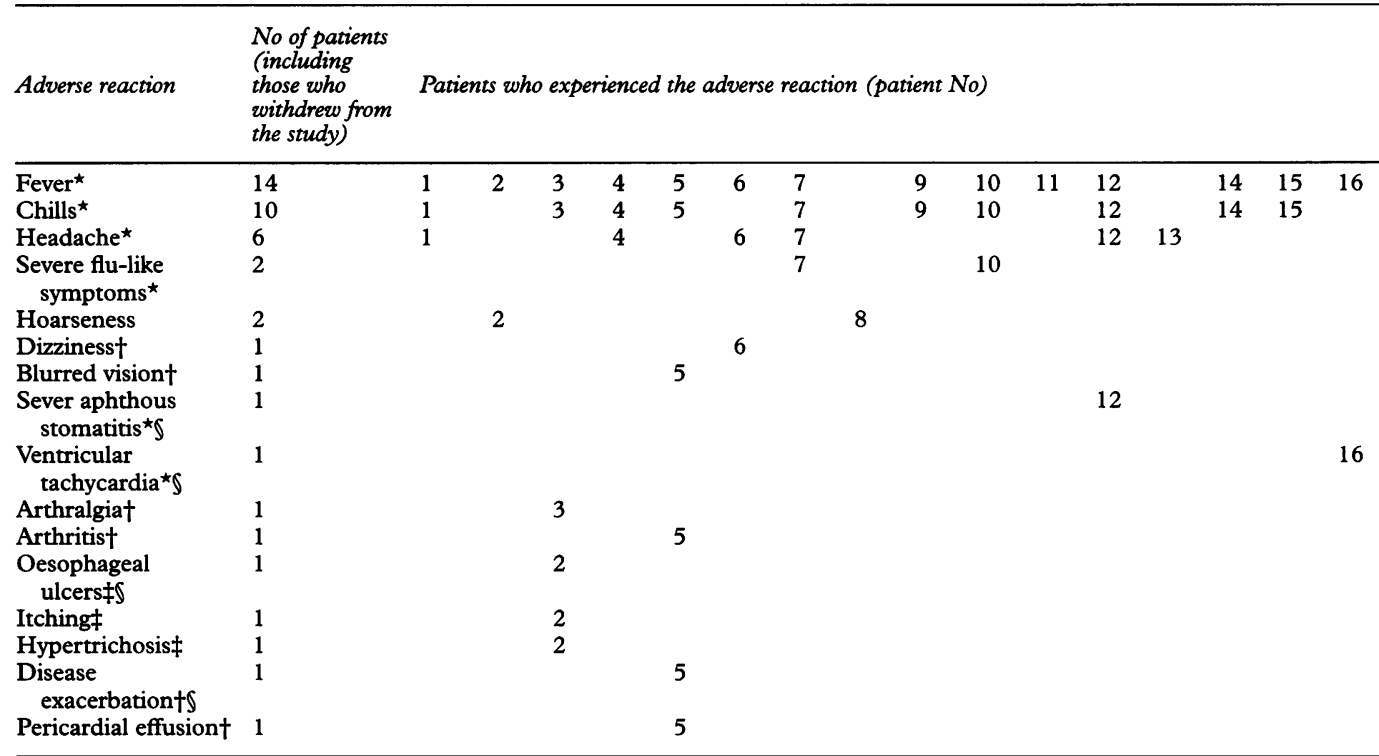

Relation to study medication: $\left({ }^{\star}\right)$ : almost certain, $(\dagger)$ : probable, $(\ddagger)$ : possible, $(\S)$ : reason for withdrawal.

the rate of reduction of cytochrome $\mathrm{C}$ according to standard protocols. The mean values (SD) of ROS production rates (nmol per 1.5 million cells $\mathrm{min}^{-1}$ ) from neutrophils of patients $(\mathrm{n}=11)$ were higher than in normal individuals $(\mathrm{n}=12)$ [8.2 (3.1) $v 5.7(2.1), \mathrm{P}<0.03]$, while after three months of treatment the mean values decreased significantly [5.1 (2.1) $v 8.2$ (3.1), $\mathbf{P}<0.01]$ and were comparable to those of normal individuals (fig 3). As shown in fig 3, reactive oxygen species decreased in all the patients except two-one with a mild increase after r-IFN $\gamma$ treatment and another with a considerable increase. The latter patient (No 5) also experienced arthritis, gastro-oesophageal reflux, and deterioration of scleroderma in the skin. Differences related to dose of r-IFN $\gamma$ were not observed.

SOLUBLE INTERLEUKIN 2 RECEPTOR CONCENTRATIONS BEFORE AND AFTER r-IFN $\gamma$ TREATMENT

The SIL-2R serum concentrations were measured at study entry and at the end of the study. Sera from 50 normal individuals were used as controls. Patients 4 and 9 were negative to SIL-2R at study entry. The remaining patients were positive, with values ranging from 500 to $2280 \mathrm{U} \mathrm{ml}^{-1}$ (median $850 \mathrm{U} \mathrm{ml}^{-1}$ ). Sera from controls gave SIL-2R concentrations ranging from 0 to $168 \mathrm{U} \mathrm{ml}^{-1}$ (median $116 \mathrm{U} \mathrm{ml}^{-1}$ ). At the end of the study the serum SIL-2R in patients 4 and 9 remained unchanged. Sera from patients 5 and 13 increased and those of the remaining patients decreased. Serum SIL2R after the treatment ranged from 0 to $1550 \mathrm{U} \mathrm{ml}^{-1}$ with a median $350 \mathrm{U} \mathrm{ml}^{-1}$. Comparison between samples on the basis of physical signs indicated that the decrease in SIL-2R after treatment was of marginal significance $(P=0.043)$. Patients at study entry also had statistically higher SIL-2R concentrations than controls $(P<0.01)$. Differences related to dose of r-IFN $\gamma$ were not observed.

\section{Discussion}

Our study describes a phase I/II open clinical trial on the toxicity, efficacy, and biological

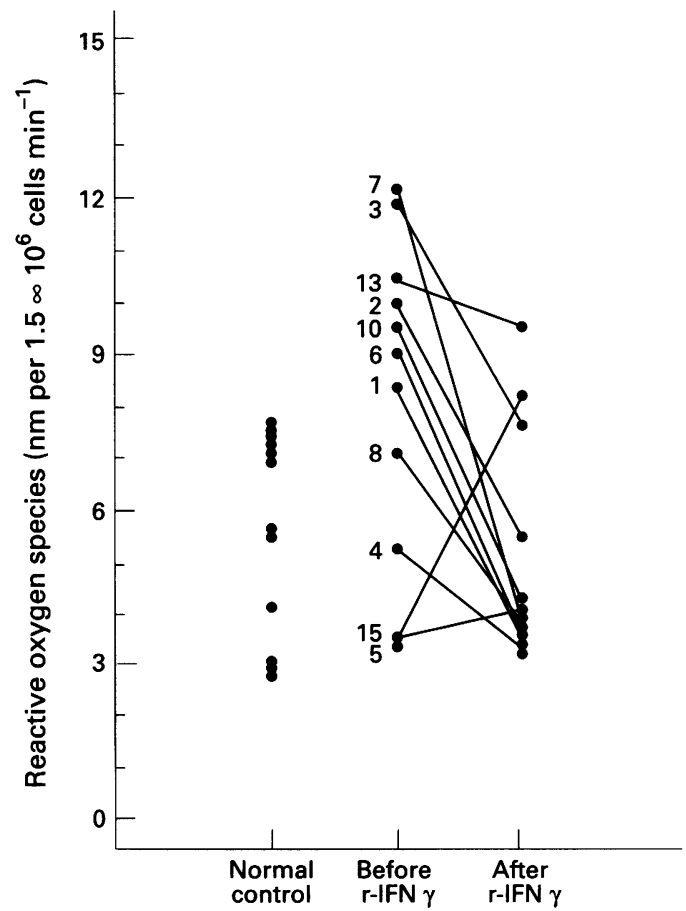

Figure 3 The reactive oxygen species (ROS) production rate (nmol per $15 \times 10^{6}$ cells min $^{-1}$ ) of peripheral neutrophils of systemic sclerosis patients before and after three months of treatment with $r-I F N \gamma$ compared to normal individuals. The ROS reduction rate was high in patients before $r-I F N \gamma$ and returned to normal levels after $r-I F N \gamma$. Numbers represent the individual patients.

effects of $r-I F N \gamma$ in the treatment of systemic sclerosis. Several phase I/II trials have been undertaken with the same purpose and have given encouraging results. ${ }^{18-20}$ A significant decrease in skin thickness score was observed at four and eight months of treatment. The decrease in skin thickness correlated with the dose and the duration of treatment with $\mathrm{r}$-IFN $\gamma$. A decrease in skin thickness has also been observed in previous studies, ${ }^{18-20}$ but no association with the dose and the duration of treatment was seen. Despite the fact that a lower dose of r-IFN $\gamma$ was used in the current study than in a previous similar study, ${ }^{20}$ we observed a greater response in terms of skin 
thickness score. This phenomenon is probably attributed to the fact that the patients in the previous study had more advanced disease in terms of the extent and severity of skin and organ involvement. The ideal therapeutic dose of $\mathrm{r}-\mathrm{IFN} \gamma$ remains controversial. In fact doses as low as $50 \mu \mathrm{g}$ per injection three times weekly ${ }^{19}$ and as high as $500 \mu \mathrm{g} \mathrm{m}^{-2}$ three times weekly $^{20}$ have been tested. The specific activities of rIFN $\gamma$ preparations used in several studies were not the same; therefore comparisons between the doses should be done with caution. Given that many patients have difficulty in tolerating a dose as high as $500 \mu \mathrm{g} \mathrm{m}^{-2}$ per injection, we think that a dose of $150 \mu \mathrm{g} \mathrm{m}^{-2}$ or $200 \mu \mathrm{g} \mathrm{m}^{-2}$ should be tested in future phase III trials. A second important finding of the current study was that internal organ involvement, in contrast to skin involvement, did not change during the study. Similar findings have also been described by others. ${ }^{20}$ Several explanations could be offered for this. (1) The patients who participated in our study had no severe internal organ involvement; therefore the disease process remained unchanged because of endogenous factors and not because of our intervention. (2) The mechanisms of internal organ damage in systemic sclerosis are dissimilar to the mechanisms responsible for skin thickening. (3) Higher doses of rIFN $\gamma$ may be more effective in treating internal organ involvement. (4) Different organs respond in a different time course. However, a sclerodermal renal crisis has been observed in a patient undergoing treatment with $\mathrm{r}$-IFN $\gamma .{ }^{20}$ This again could be a result of the natural course of disease progression and not due to the intervention. Changes in DLCO and LVEF did not reach statistical significance during the study, as also observed by others, ${ }^{19}{ }^{20}$ and in contrast to a significant increase in DLCO observed in one study. ${ }^{18}$

Nearly one quarter of our patients met criteria for discontinuation of the drug. Side effects were subcategorised as almost certainly, probably, and possibly related to rIFN $\gamma$. Fever and chills, headache, and severe flu-like symptoms were the most common symptoms and were also certainly related to r-IFN $\gamma^{18-20}$ Nearly $90 \%$ of patients experienced fever, but the intensity of this reaction was ameliorated by paracetamol. Fever could be the result of activation of macrophages by IFN $\gamma$, with consequent production of interleukin- 1 and hypothalamic stimulation. Alternatively, IFN $\gamma$ could suppress TH2 lymphocytes which secrete interleukin-10, a potent inhibitor of macrophage activation; therefore, macrophages are activated from products derived from tissue injury in scleroderma, in the absence of downregulatory effects of interleukin-10. Fever, chills, severe flu-like symptoms, and headache were not reasons for discontinuing the treatment. Our patients complained of adverse reactions during the first five months of treatment and they described the greatest response to the therapy during the first two months. The rapid decrease of skin thickness score can be attributed to the decrease of subcutaneous oedema which is not an uncommon manifestation of scleroderma. Other studies have also shown similar results. ${ }^{26}$ Arthralgia but not arthritis has been linked with r-IFN $\gamma$ treatment $^{1920}$ and occurred in one of our patients who had only a marginal response to r-IFN $\gamma$. However, the frank arthritis that occurred in this case cannot be considered a definite side effect of rIFN $\gamma$; it may simply have been a manifestation of disease exacerbation.

Exacerbation of systemic sclerosis may be an inevitable result of the disease process itself and not due to our intervention. An effort was made to search for the effects of rIFN $\gamma$ on biological variables reflecting the presumed underlying mechanism of the drug. We concentrated on two indices known to be associated with the extent and the severity of the disease-the rate of production of reactive oxygen species from peripheral neutrophils ${ }^{13}{ }^{14}$ and the serum concentrations of SIL- $2 R^{26}$ in patients before and after r-IFN $\gamma$ treatment.

Enhanced oxidative metabolism of peripheral neutrophils from patients with systemic sclerosis has been reported $d^{132728}$ and increased concentrations of substances such as malondialdehyde, which are produced by oxidative agents, have also been observed in the plasma of patients with systemic sclerosis. ${ }^{14}$ Furthermore, an increased susceptibility to oxidation of low density lipoproteins isolated from patients with systemic sclerosis has been described and attributed to high ROS concentrations and to low levels of antioxidants, especially ascorbate, in systemic sclerosis patients. ${ }^{29}$ Reactive oxygen species can cause several abnormalities related to systemic sclerosis, such as endothelial cell damage,${ }^{10}$ enhanced platelet activation, ${ }^{30}$ increased frequency of chromosomal breaks, ${ }^{31}{ }^{32}$ loss of functional protease inhibitors, ${ }^{33}$ and oxidation of low density lipoproteins (LDL) ${ }^{29}$ Oxidised LDL activate T cells, ${ }^{34}$ increase the release of interleukin- $1 \beta,{ }^{35}$ induce the expression of genes which encode adhesion molecules in endothelial cells, ${ }^{36}$ and increase the expression of platelet derived growth factor from smooth muscle cells. ${ }^{37}$ It is therefore plausible that activated neutrophils may represent a pathophysiological mechanism in systemic sclerosis. Neutrophils do not always generate reactive oxygen species. Under the influence of a variety of factors, these cells may increase their capacity of producing ROS after stimulation, a phenomenon called "priming". ${ }^{38}$ IFN $\gamma$ in particular has been regarded generally as an inducer of ROS secretion by neutrophils ${ }^{39}$ 40 and this finding encouraged its use in patients with chronic granulomatous disease, with considerable success. ${ }^{41}$ However, even in chronic granulomatous disease the clinical response was not in accordance with the changes in superoxide generation from neutrophils after r-IFN $\gamma$ treatment, since these changes were insignificant. ${ }^{41}$ Therefore, knowledge of the previous functional status of neutrophils and their microenviroment is essential in predicting their response to r-IFN $\gamma$. Further research is necessary to clarify the exact role of IFN $\gamma$ on neutrophils in systemic sclerosis patients. We simply wished here to use 
the reduced generation of reactive oxygen species by neutrophils of systemic sclerosis patients as an indicator of some biological action of the drug which might alter the disease process, since large amounts of ROS are found in systemic sclerosis patients compared to normal individuals. ${ }^{13} 1428$

High levels of SIL-2R were also found at study entry in the sera of all the patients except two. The SIL-2R levels tended to decrease in all patients. The exceptions were patient No 5, who had disease exacerbation, and patient No 4 who had a good response.

In conclusion, our report offers data which suggest that $\mathrm{r}$-IFN $\gamma$ is relatively safe in the treatment of systemic sclerosis, at least in the dose of $150 \mu \mathrm{g} \mathrm{m}^{-2}$ three times weekly and is effective for skin involvement. A decrease in skin thickness score and the expression of side effects from the first five months of treatment could be good indicators for response, non-response, or a tendency to develop side effects.

We wish to thank Boehringer-Ingelheim HELLAS SA for financial support, Dr Panayiotis Dimitriou for his assistance in statistical analysis, Drs Maria Maniati, M Achenbach and P Lathridou for their assistance in evaluating the patients, and Mrs. Pola Papadopoulou and Lena Goules for excellent secretarial assistance. Supported by a grant from Boehringer-Ingelheim Hellas SA.

1 Gilliland BC. Systemic sclerosis (scleroderma). In: Isserbacher KJ, Braunwald E, Wilson JD, Martin JB, Fauci AS, Kasper DL, eds. Harrison: Principles of internal medicine, 13th ed (international edition). New York: McGraw-Hill, 13th ed (internati

2 Le Roy EC. Connective tissue synthesis by scleroderma skin fibroblasts in cell culture. F Exp Med 1972;135:1351-62.

3 Uitto J, Bauer EA, Eisen AZ. Scleroderma: increased biosynthesis of triplehelical type I and II procollagens associated with unaltered expression of collagenase by skin fibroblasts in culture. $\mathcal{F}$ Clin Invest 1979;64:921-30.

4 Roumm AD, Whiteside TL, Medsger TA, Rodnan GP. Lymphocytes in the skin of patients with progressive systemic sclerosis: quantification, subtyping, and clinical correlations. Arthritis Rheum 1984;27:645-53.

5 Fleischmajer R, Perlish JS, Reeves JRT. Cellular infiltrates in scleroderma skin. Arthritis Rheum 1977;20:975-84.

6 Freundlich B, Bomalaski JS, Neilson E, Jimenez SA. Regulation of fibroblast proliferation and collagen synthesis by cytokines. Immunol Today 1986;7:303-7.

7 Le Roy EC, Smith EA, Kahaleh MB , Trojanowska M, Silver RM. A strategy for determining the pathogenesis of systemic sclerosis. Arthritis Rheum 1989;32:817-25.

8 Norton WL, Nardo JM. Vascular disease in progressive systemic sclerosis (scleroderma). Ann Intern Med 1970; 73:317-24.

9 Kahaleh M B, Obsorn I, Le Roy E C. Increased factor VIII/ von Willebrand factor antigen and von Willebrand factor activity in scleroderma and Raynauds phenomenon. Ann Intern Med 1981;94:482-4.

10 Kahaleh MB, Sherer GK, Le Roy EC. Endothelial injury in scleroderma. F Exp Med 1979;149:1326-35.

11 Roberts AB, Sporn MB, Assoian RK, Smith JM, Roche NS, Wakefield LM, et al.Transforming growth factor type B: rapid induction of fibrosis and angiogenesis in vivo and rapid induction of fibrosis and angiogenesis in vivo and stimulation of collagen format

12 White B, Bauer EA, Goldsmith LA, Hochberg MC, Katz $\mathrm{LM}$, Korn $\mathrm{JH}$, et al. Guidelines for clinical trials in systemic sclerosis (scleroderma). Arthritis Rheum 1995; 38:351-60

13 Maslen CL, Hall ND, Woolf AD, Maddison PJ. Enhanced oxidative metabolism of neutrophils from patients with systemic sclerosis. Br f Rheumatol 1987;26:113-7.

14 Law CS, Sridges AB, Muir A, Scott N, Bancroft A, Belch JJF. Further evidence of increased polymorphonuclear cell activity in patients with Raynauds phenomenon. $B r f$ Rheumatol 1992;31:375-80

15 Jimenez SA, Freundlich B, Rosenbloom J. Selective inhibition of human diploid fibroblast collagen synthesis by interferons. $\mathcal{F}$ Clin Invest 1984;74:1112-6.
16 Duncan MR, Berman B. Gamma interferon is the lymphokine and beta interferon the monokine responsible for inhibition of fibrocast collagen production and latebut not early fibroblast proliferation. If Exp Med 1987; 162:516-27.

17 Czaja $M$, Weier FR, Eghbali $M$, Giambrone $M$, Mahboubah I, Zern MA. Differential effects of gamma interferon on collagen and fibronectin gene expression. $\mathcal{F}$ Biol Chem 1987;262:13348-51.

18 Kahan A, Amor B, Menkes CJ, Stauch G. Recombinant interferon gamma in the treatment of systemic sclerosis. Am $\mathcal{F}$ Med 1989;87:273-7.

19 Hein R, Becr J, Hundgen M, Hunzelmann N, Meurer M, Braun-Falco $\mathrm{O}$, et al. Treatment of systemic sclerosis with $\gamma$-interferon. Br $\mathcal{F}$ Dermatol 1992;126:496-591.

20 Freudlich B, Jiminez SA, Steen VD, Medger JA, Szkolnickin $M$, Jaffe HS.Treatment of systemic Sclerosis with recom binant interferon- $\gamma$. Arthritis Rheum 1992;35:1134-42.

21 Le Roy EC, Black C, Fleischmajer R, Jablonska S, Krieg T, Medsger JA, et al. Scleroderma (systemic sclerosis) classification, subsets and pathogenesis. $\mathcal{f}$ Rheumatol 1988 15:202-5.

22 Watters LC, King TE, Schwa MI, Waldron JA, Stanford RE, Cherniak RM. A clinical, radiologic and physiologic scoring system for the longitudinal assesment of patients with idiopathic pulmonary fibrosis. Annu Rev Respir Dis 1986;133:97-103.

23 Kahaleh MB, Sultany GL, Smith HH, Huffstutter JE, Loadbolt CB, LeRoy EC. A modified scleroderma skin scoring method. Clin Exp Rheumatol 1986;4:367-9.

24 Verheijen R, Salden M, Van Venrooij WT. Protein blotting. In: Van Venrooij WT, Maini RN, eds. Manual of biological markers of disease. Amsterdam: Kluwer Academic Publishers, 1993;A4:1-25.

25 Markert M, Andrews PC, Babior BM. Measurement of $\mathrm{O}_{2}$ production by human neutrophils. The preparation and assay of NADPH oxidase-containing particles from human neutrophils. Methods Enzymol 1984;105:358-63.

26 Polisson RP, Gilkeson GS, Pyun EH, Pisetsky DS, Smith EA, Simon LS. A multicenter trial of recombinant human interferon-gamma in patients with systematic sclerosis: effects on cutaneous fibrosis and interleukin-2 receptor effects on cutaneous fibrosis and

$27 \mathrm{Kahaleh}$ MB. Soluble immunologic products in scleroderma sera. Clin Immunol Immunopathol 1991;58:139-44.

28 Murrel DF. A radical proposal for the pathogenesis of scleroderma. $\mathcal{F}$ Am Acad Dermatol 1993;28:78-85.

29 Bruckdofer KR, Hillary JB, Bunce T, Vancheeswaran $R$, Black CM. Increased susceptibility to oxidation of low-density lipoproteins isolated from patients with systemic sclerosis. Arthritis Rheum 1995;38:1060-7.

30 Carpentier H, Maricq HR. Microvasculature in systemic sclerosis. Clin Exp Rheumatol 1990;16:75-92.

31 Sherer G, Jackson BB, LeRoy EC. Chromosomal break age and sister chromatid exchange frequencies in Scleroderma. Arthritis Rheum 1981;24:1409-13.

32 Emmerit I. Reactive oxygen species, chromosome mutation and cancer: possible role of clastogenic factor in carcinogenesis. Free Radic Biol Med 1994;16:99-109.

$33 \mathrm{Kahaleh} \mathrm{MB,} \mathrm{LeRoy} \mathrm{EC.} \mathrm{Endothelial} \mathrm{injury} \mathrm{in} \mathrm{scleroderma.}$ A protease mechanism. f Lab Clin Med 1983;101:553-60.

34 Frostegard J, Wu RH, Giscombe R, Holm G, Lefvert AK, Nilsson J. Induction of T-cell activation by oxidised low density lipoprotein. Arterioscler Thomb 1992;12:461-7.

$35 \mathrm{Ku} \mathrm{G}$, Thomas CE, Akkenson AL, Jackson RL. Induction of interleukin 1 beta expression from peripheral blood interleukin 1 beta expression from peripheral blood enoic acid. $₹$ Biol Chem 1992;267:14183-8.

36 Berlimer JA, Territo MC, Sevanian A, Ramin S, Kim JA, Bamshad B, et al. Minimally modified low density lipoprotein stimulates monocyte endothelial interactions. $\mathcal{f}$ Clin Invest 1990;85:1260-6.

37 Zwijsen RML, Japenga SC, Heijen AMP, Vendenbos RC, Koeman $\mathrm{JH}$. Induction of platelet derived growth factor- $\alpha$ gene expression in human smooth muscle cells by oxidized low density lipoproteins. Biochem Biophys Res Commun 1992;186:1410-6.

38 Bass DA, Genard C, Olbranzt P, Wilson J, McCall CE, McPhail LC. Priming of the respiratory burst of McPhail LC. Priming of the respiratory burst of
neutrophils by diacylglycerol. $f$ Biol Chem $1987 ; 262: 6643-$ 9.

39 Shalaby MR, Aggarwal BB, Rinderkecht E, Svedersky LP, Finkle BS, Palladino MA. Activation of human polymorphonuclear neutrophil functions by interferon- and tumor necrosis factors. F Immunol 1985;135:2069-73.

40 Cassatela M A, DellaBianca V, Berton G, Rossi F. Activation by gamma interferon of human macrophage to produce toxic oxygen molecules is accompanied by decreased $\mathrm{Km}$ of the superoxide-generating NADPH oxidase. Biochem Biophys Res Commun 1985; 132:908-14.

41 The International Chronic Granulomatous Disease Cooperative Study Group. A control trial of interferon gamma to prevent infection in chronic granulomatous disease. $N$ Engl ₹ Med 1991;324:509-16. 